Carta ao Editor

Letter to the Editor

Bárbara Niegia Garcia de Goulart ${ }^{1}$ (1)

Paula Anderle ${ }^{1}$ (C)

\section{Reabilitação: uma demanda que cresce e merece atenção}

\section{Rehabilitation: a rising demand that calls for action}

Segundo a Organização Mundial de Saúde (OMS), mais de 200 milhões de pessoas têm dificuldades funcionais ${ }^{(1)}$, sendo que $92 \%$ da carga global de doenças pode se beneficiar de recursos de reabilitação ${ }^{(2)}$.

$\mathrm{Na}$ última década, houve um aumento substancial na demanda por reabilitação e espera-se que esta demanda aumente nos próximos anos. Isso se deve, principalmente, ao aumento da expectativa de vida ao nascer, ao aumento global da expectativa de vida e da carga de doenças crônicas não transmissíveis (DCNT) e comorbidades.

A reabilitação engloba um conjunto de medidas que auxiliam os indivíduos com incapacidades a alcançar/manter um ótimo funcionamento integrado com seus ambientes ${ }^{(1)}$. Uma das medidas para quantificar a perda de saúde são os anos vividos com incapacidade (years living with disability - YLDs). Considerando globalmente que, entre 1990 e 2017, três tipos de DCNT (dor lombar, cefaleia e depressão) prevaleceram entre as quatro principais causas de YLDs, causando 162 milhões (95\% UI 118-216) de YLDs somente em $2017^{(3)}$, é fundamental que os sistemas de saúde estejam preparados para lidar com estes quantitativos de pessoas em situação de vulnerabilidade, principalmente com quadros piores quando coexistentes.

Parte importante dos agravos que levam a YLDs é passível de tratamento e reabilitação, desde que haja acesso a cuidados em tempo oportuno. Quando não tratados de forma apropriada, podem ocasionar diminuição na qualidade de vida, restrições de independência e na participação social, educacional e laboral, impactando a autossustentabilidade dos indivíduos.

Pela complexidade do tema, em 2017, os membros da OMS reuniram-se com representantes governamentais, estudiosos, usuários e demais interessados para discutir estratégias de ação coordenada mundial e estabelecer compromissos conjuntos, para elevar a reabilitação como estratégia de saúde relevante para toda a população. A proposta pretende dar conta das metas do desenvolvimento sustentável, afiançando o continuum de cuidados para “[...] garantir vidas saudáveis e promover o bem-estar para todos em todas as idades"(4:15).

Assim, publicou-se o relatório Rehabilitation 2030: A Call for Action, objetivando atentar para o aumento na procura por serviços de reabilitação e a necessidade de ações globais que fortaleçam a reabilitação nos sistemas de saúde ${ }^{(4)}$. Anteriormente, a Organização das Nações Unidas (ONU) recomendou que os países reforçassem e ampliassem serviços e programas de reabilitação, iniciando-os o mais cedo possível, com base em avaliações multidisciplinares das necessidades dos indivíduos, incluindo dispositivos e tecnologias $\operatorname{assistivas}^{(1,5)}$.

Trabalho realizado na Universidade Federal do Rio Grande do Sul - UFRGS - Porto Alegre (RS), Brasil.

${ }^{1}$ Programa de Pós-graduação em Epidemiologia, Universidade Federal do Rio Grande do Sul - UFRGS - Porto Alegre (RS), Brasil.

Fonte de financiamento: $\mathrm{CNPq}$ (bolsa de pesquisa), processo ${ }^{\circ}$. 305243/2018-7.

Conflito de interesses: nada a declarar. 
No Brasil, programas governamentais apresentam diretrizes para organização e planejamento dos serviços ${ }^{(6)}$, como o Centro Especializado de Reabilitação, tendo o objetivo de fornecer reabilitação, mediante recurso profissional especializado, atuando com base epidemiológica e utilizando tecnologia apropriada para desenvolver essas ações. Dentre os procedimentos que compõem a reabilitação no SUS, destacam-se os procedimentos especializados realizados por médicos, outros profissionais de níveis superior e médio, terapias especializadas e realização de próteses e órteses ${ }^{(7)}$.

A OMS enfatiza barreiras e necessidades para fortalecimento dos serviços de reabilitação, como: falta de prioridade dos governos, de políticas específicas de reabilitação, de integração entre os sistemas de saúde e sociais envolvidos neste processo, de profissionais capacitados, de instalações e equipamentos adequados, além de financiamento escasso ou inexistente ${ }^{(4)}$. Os programas brasileiros mencionados visam reduzir essas barreiras e coordenar os serviços; no entanto, existem latências entre demanda, oferta e acesso dos usuários.

De acordo com os resultados da Pesquisa Nacional de Saúde (2013), a proporção da população brasileira com deficiência que utiliza os serviços de reabilitação ainda é reduzida. O acesso à reabilitação é maior nas pessoas com deficiência intelectual $(30,4 \%)$, seguida dos deficientes físicos $(18,4 \%)$, auditivos $(8,4 \%)$ e visuais $(4,8 \%)^{(8)}$. Assim, é importante atentar para estes dados e reconhecer as limitações que permeiam os serviços públicos disponibilizados.

Há necessidade de que líderes e gestores mundiais debatam o tema e centralizem esforços para incluí-lo nas agendas de saúde de seus países, com políticas e ações públicas que visem reduzir as limitações encontradas nos processos de reabilitação. Tais medidas devem atentar para o aumento na demanda e para as dificuldades na oferta, como falta de recursos financeiros para aquisição de tecnologias, falta de recurso humano especializado e de educação continuada, além das limitações no acesso, com barreiras físicas e arquitetônicas.

Seguindo a reflexão da OMS acerca das barreiras no processo de reabilitação e pensando na hierarquização e regionalização do SUS, medidas podem ser pensadas nas três esferas de gestão. O governo federal poderia reforçar a criação e revisão de políticas públicas direcionadas para reabilitação e para o uso de novas tecnologias e formas de atuação que atendam a demandas do século XXI (visto que ainda estão calcadas em pressupostos do século XX), bem como aumentar a fiscalização das verbas destinadas à reabilitação. Aos governos estaduais, caberia integrar os sistemas de saúde, diminuindo a burocracia e facilitando o acesso aos serviços, além de melhorias nas instalações e acessibilidade e na aquisição de tecnologias de ponta. Aos municípios, caberia buscar parcerias para melhorar a oferta do serviço, a gestão de recurso humano especializado, a educação permanente dos profissionais e a educação em saúde dos usuários, buscando ação conjunta relativa à reabilitação.

Ainda, é fundamental refletirmos sobre a atuação dos profissionais que ofertam reabilitação e estão em contato direto com a população atendida. Estes devem repensar o fazer clínico, observando e utilizando tecnologias leves disruptivas, como frequência de atendimento, encaminhamentos, matriciamentos, orientações de atividades com automonitoramento domiciliar, visando à autonomia dos usuários.

A reabilitação e o acesso aos serviços não devem ser pauta somente dos sistemas de saúde. É fundamental que parcerias dos serviços de reabilitação envolvam todos os usuários, visto que esta demanda se dá em diversas etapas da vida, em momentos específicos ou contínuos, por doenças e agravos variados. Mesmo que a continuidade do cuidado seja prioritariamente da saúde, a reabilitação é um investimento em capital humano que contribui para a promoção da saúde e qualidade de vida, bem como para o desenvolvimento econômico e social.

\section{REFERÊNCIAS}

1. WHO: World Health Organization. World report on disability. Switzerland: WHO; 2011

2. Gupta N, Castillo-Laborde C, Landry MD. Health-related rehabilitation services: assessing the global supply of and need for human resources. BMC Health Serv Res. 2011;11(1):276. http://dx.doi.org/10.1186/14726963-11-276. PMid:22004560.

3. James SL, Abate D, Abate KH, Abay SM, Abbafati C, Abbasi N, et al. Global, regional, and national incidence, prevalence, and years lived with disability for 354 diseases and injuries for 195 countries and territories, 1990-2017: a systematic analysis for the Global Burden of Disease Study 2017. Lancet. 2018;392(10159):1789-858. http://dx.doi.org/10.1016/ S0140-6736(18)32279-7. PMid:30496104.

4. WHO: World Health Organization. Rehabilitation 2030: a call for action: meeting report [Internet]. Switzerland: WHO; 2017 [cited 2019 May 2]. Available from: http://www.who.int/disabilities/care/rehab-2030/en/

5. Lynch E, Hillier S, Cadilhac D. When should physical rehabilitation commence after stroke: a systematic review. Int J Stroke. 2014;9(4):468 78. http://dx.doi.org/10.1111/ijs.12262. PMid:24636633.

6. Brasil. Ministério da Saúde. Portaria n ${ }^{\circ} 793$, de 24 de abril de 2012. Institui a rede de cuidados à pessoa com deficiência no âmbito do Sistema Único de Saúde. Diário Oficial da União [Internet]; Brasília; 25 abril 2012 [cited 2019 May 2]. Available from: http://bvsms.saude.gov.br/bvs/saudelegis/ gm/2012/prt0793_24_04_2012.html

7. Brasil. Conselho Nacional de Secretários de Saúde. Assistência de média e alta complexidade no SUS [Internet]. Brasília: CONASS; 2007. 248 p. [cited 2019 May 2]. Available from: http://bvsms.saude.gov.br/bvs/ publicacoes/colec_progestores_livro9.pdf

8. Malta DC, Stopa SR, Canuto R, Gomes NL, Mendes VLF, Goulart $\mathrm{BNG}$, et al. Prevalência autorreferida de deficiência no Brasil, segundo a Pesquisa Nacional de Saúde, 2013. Cien Saude Colet. 2016;21(10):3253-64 http://dx.doi.org/10.1590/1413-812320152110.17512016. PMid:27783798.

\section{Contribuição dos autores}

BNGG e PA participaram da concepção, análise das referências, redação e revisão da versão final do manuscrito. 